\title{
STEM Through Authentic Research and Training Program (START) for Underrepresented Communities: Adapting to the COVID-19 Pandemic
}

\author{
Luke H. Bradley ${ }^{1,2,3}$, Brittany N. Derr ${ }^{4}$, Catherine E. Durbin ${ }^{1,3}$, Michael J. Lauer ${ }^{5}$, Fara Williams ${ }^{6}$, Anthony P. Sinai ${ }^{7}$, \\ Julie A. Bradley ${ }^{4}$, and Margaret Mohr-Schroeder ${ }^{8}$ \\ ${ }^{1}$ Departments of Neuroscience, ${ }^{2}$ Molecular and Cellular Biochemistry, and ${ }^{7}$ Microbiology, Immunology, Molecular Genetics, University of Kentucky College of \\ Medicine, Lexington, KY; ${ }^{3}$ Lewis Honors College, ${ }^{4}$ Academic Coaching and Transformative Learning, and ${ }^{6}$ Kentucky-West Virginia Louis Stokes Alliance for \\ Minority Participation Program, University of Kentucky, Lexington, KY; ${ }^{5}$ STEAM Academy, Fayette County Public Schools, Lexington, KY; and ${ }^{8}$ Department of STEM \\ Education, University of Kentucky College of Education, Lexington, KY \\ Keywords: Distance Learning, Exomedicine, Coaching, Mentoring \\ Publication Date: October 4, 2021 \\ DOI: https://doi.org/10.15695/jstem/v4i4.01
}

\begin{abstract}
The STEM Through Authentic Research and Training (START) Program is a new program integrating academic, social, and professional experiences, in the theme of exomedicine, to build a pipeline into college for first generation and traditionally underrepresented students by providing year-round authentic opportunities and professional development for high school students and teachers. In response to the COVID-19 pandemic, the START Program has worked with the local Fayette County public school and community partners to provide content to over 300 students through: virtual laboratory tours with community partner Space Tango, "meet a scientist" discussions, and online near-peer student demonstrations aimed at making the practice of STEM disciplines approachable. Furthermore, the START Program has partnered with Higher Orbits to provide at-home, space-themed learning kits for students to develop teamwork, communication, and STEM principles while engaging in online content with teachers, professionals, and astronauts. Finally, the START Program has moved its training platforms online, including receiving College Reading and Learning Association (CRLA) Peer Educator accreditation for our near-peer mentoring and coaching training. As a result, the START Program is better positioned to address this critical need in STEM education, while reaching more students in the community than possible with face-to-face interactions alone.
\end{abstract}

\section{INTRODUCTION}

The impact of science, technology, engineering, and mathematics (STEM) is felt in our daily lives, directly impacting every individual on the planet. This results in a rapidly advancing STEM industry competing for a highly skilled labor pool. According to the U.S. Department of Commerce Economics and Statistics Administration (2017), employment in STEM occupations has grown much faster than employment in non-STEM occupations over the last decade (24.4 percent versus 4.0 percent, respectively), and STEM occupations are projected to grow by 8.9 percent from 2014 to 2024, compared to 6.4 percent growth for nonSTEM occupations. Along with STEM occupations being one of the fastest growing fields in the U.S., $83 \%$ of STEM occupations offer wages above the national average (Fayer et al., 2017). However, despite the fast growth in STEM industries, first generation, low income, people of color, women, and people with disabilities are underrepresented in the workforce (Huggett, 2018). According to the National Cen-

ter of Education Statistics, underrepresented individuals significantly lag in national 6-year graduation outcomes with STEM degrees at 4-year institutions (Hussar et al., 2020). Targeting students in high school and middle school has long been a foundation for the development of the STEM workforce, however gaps in the pipeline need to be addressed; the recruitment of underrepresented populations into STEM fields is often lagging (Muzzatti and Agnoli, 2007; Elam et al., 2012; Huggett, 2018).

\section{OBSTACLES FOR UNDERREPRESENTED STUDENTS IN STEM}

Underrepresented students often lack feelings of belongingness, self-efficacy, and academic resilience (Strayhorn, 2011; Jong et al., 2020). These perceptions are often attributed to the lack of underrepresented individuals in academic and STEM professional settings, leading underrepresented 


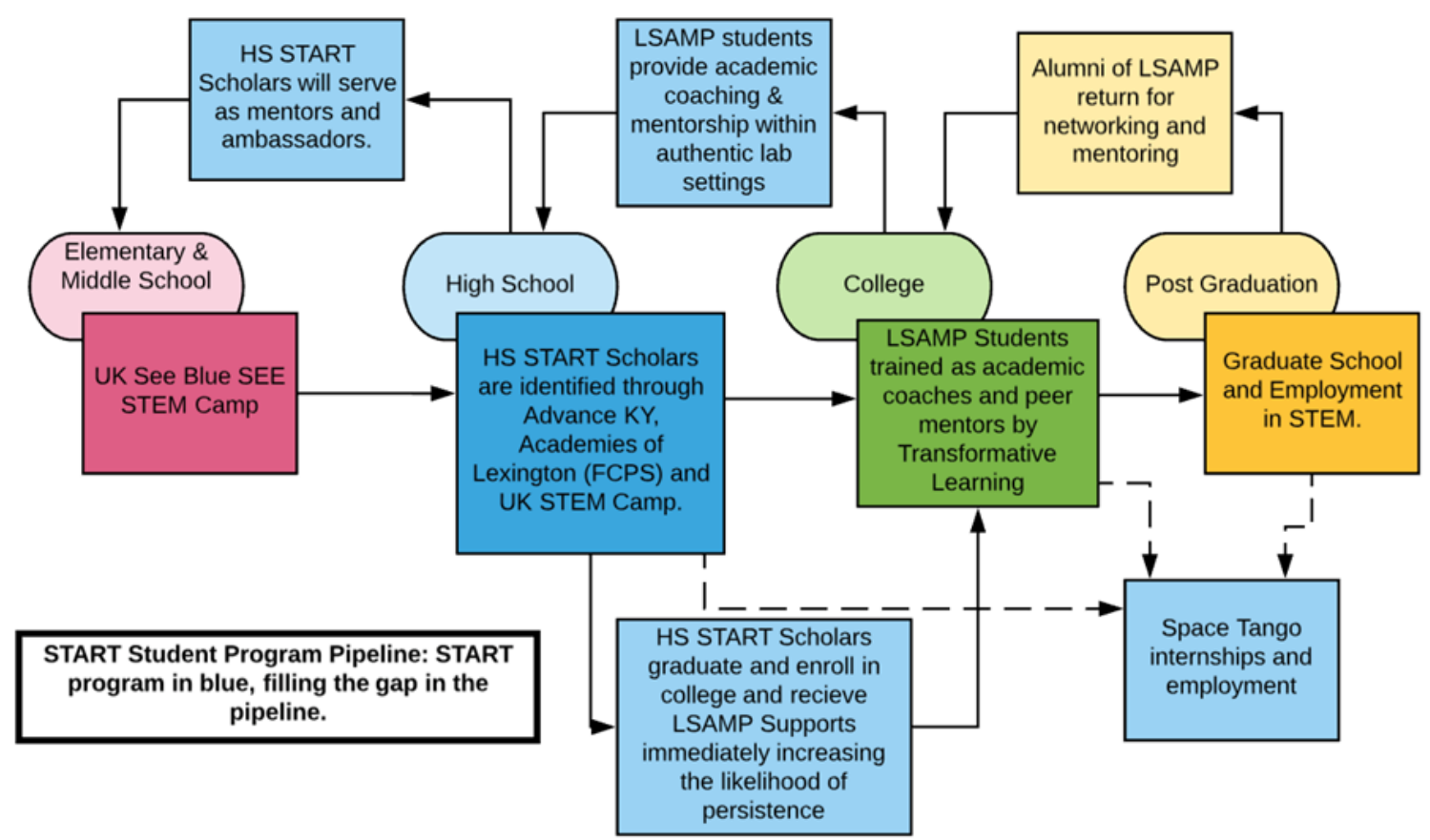

Figure 1. START Student Program Pipeline. The START pipeline seeks to provide seamless scaffolding of student learning from program to program by utilizing inquiry-based learning and authentic STEM experiences, producing better prepared students as they move up the pipeline. Each program is designed to create access and opportunity and to support underrepresented students in STEM in a developmentally appropriate way and decreasing "melt" from program to program by using highly trained near-peer/peer mentors/ coaches. As students progress in the pipeline, they are trained and become the next group of near-peer STEM role models and mentors.

students to believe they would not "fit in" in these environments, thereby increasing stress and dissatisfaction (Jong et al., 2020). The combination of these issues results in low graduation rates for underrepresented students in STEM and a phenomenon known as "melt", where students who are eligible for college do not attend (Castleman and Page, 2015). The absence of a feeling of belonging can lead to students questioning their abilities, doubting they will meet the expectations of the university, while increasing their stress and disconnection from the school body and the collegiate experience in general. Collectively, these factors result in an absence of peer and near-peer role models, lack of opportunity to engage in high-quality, authentic research experiences, and isolation from college and STEM careers for underrepresented populations.

It has been long recognized that authentic learning, across a variety of settings and disciplines increases motivation to learn, develops a deeper understanding of content and its application, increases knowledge of professional conduct, and provides experiences to practice working through real-life challenges (Johri and Olds, 2011; Edmonds-Cady and Sosulski, 2012; Mohr-Schroeder et al., 2014; Roberts et al., 2018). Across the country, P12 schools are making progress toward providing students with inquiry and project-based learning to increase engagement and rigor, and to better prepare students for college and beyond (Maxwell and Ruben, 2002; Kemple and Willner, 2008). Schools can enlist partners to provide rigorous, authentic learning experiences from ex- perienced and trained mentors, providing underrepresented students with another opportunity to strengthen both cognitive and non-cognitive skills that will be useful later in life.

Underrepresented students face a variety of obstacles in reaching academic success within the STEM field. Addressing factors such as deficits in social capital, self-efficacy and sense of belongingness, social and academic support are essential to increasing diversity within STEM. In addition to increasing the number of underrepresented students in these fields, it is essential to increase the quality of education and experiences available to students (Jackson et al., 2021). Providing students with a productive and steady progression through the STEM pipeline depends on access to opportunity, meaningful experiences, and support (Chang et al., 2014). Additionally, by providing out-of-school activities, students have more opportunities to connect with faculty and peers, increasing social capital, as well as increasing sense of belonging and self-efficacy.

\section{THE UK START PROGRAM FOR UNDERREPRESENTED COMMUNITIES}

The University of Kentucky (UK) STEM Through Authentic Research Training (START) Program aims to address these challenges by creating a STEM ecosystem (see Figure 1) that specifically focuses on recruitment and retention of first generation and underrepresented populations in STEM. It does so by providing opportunity and access to year-round 
research and professional development activities for students and teachers, thus providing participants a stronger sense of knowledge of the profession, preparation and mentorship for higher education, and a sense of belonging within STEM. With our underlying hypothesis, that strategies that foster the academic, social, and professional integration of underrepresented students throughout the P12 pipeline are needed to increase recruitment and retention in STEM, the START Program expands Tinto's student retention focus on academic and social integrations (Tinto, 2007). We achieve this by adding a third focus: access to opportunity (a 3:1 support model) and shifting the paradigm to include middle school and high school students. The gap in the pipeline from high school students to college (and beyond) will be filled by the authentic learning experiences offered by the START Program with campus and community partners, as seen in Figure 1.

To help with the recruitment of students from all STEM disciplines, the theme of the START Program's authentic research opportunities is exomedicine, the field of conducting biomedical research in the microgravity of space to discover breakthroughs to help human health (Figure 2). Innovation and trans-disciplinary collaboration are at the heart of this STEM discipline. Students will have the opportunity to engage and participate in projects that have the potential to be developed for launch to the International Space Station (ISS) with our local company partner, Space Tango (https:// spacetango.com). To improve recruitment and retention of underrepresented populations in the STEM pipeline, the START Program's research education plan targets current high school students and their STEM teachers to improve early interest of underrepresented populations in STEM.

The START Program was initially developed (pre-pandemic) as an integrated outreach program that spans through grades P12. Beginning in elementary and middle school, students, especially from underrepresented groups, were to be invited to participate in the UK Summer STEM Experiences (Mohr-Schroeder et al., 2014) where they would engage with STEM faculty in hands-on, authentic STEM learning experiences aimed at increasing their STEM literacy. These students, and high school students from partner schools, would continue participating in in-school and out-of-school programming throughout the year, such as tours, demonstrations, and networking/invitations to campus STEM events. All students that participate in programming are identified as START Ambassadors to begin to build an association with STEM. Following an application process, selected high school students (grades 11-12) would come to the University of Kentucky to engage in year-round authentic learning laboratory experiences (START Apprentices). Relying on near-peer mentoring, current undergraduate scholars (recruited from the campus Louis Stokes Alliance for Minority Participation, LSAMP, STEM program for student

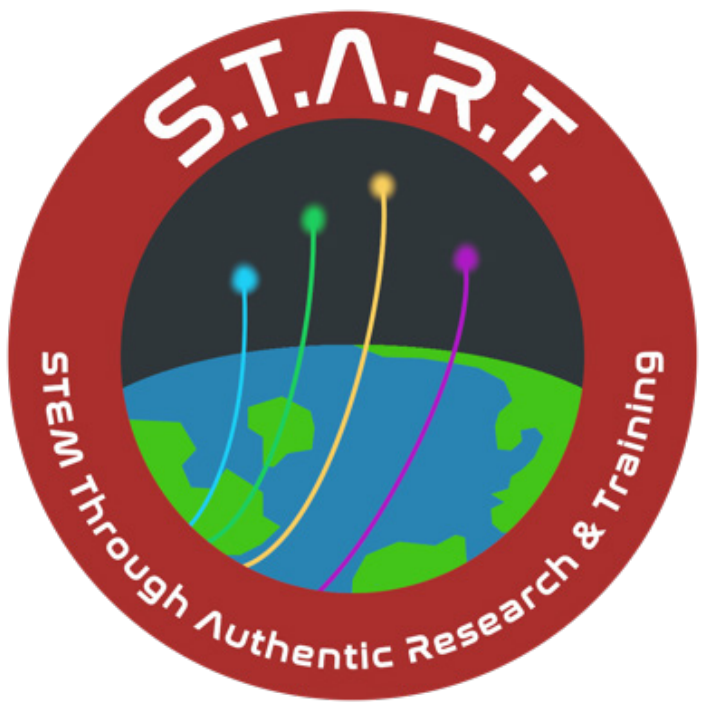

Figure 2. START Mission Patch Logo. In the theme of space missions, the START Program has designed a logo that is printed on stickers, patches, and face masks to provide to students, teachers, and community partners to build a sense of belonging in the program. Future logos will be designed by START Apprentices to further build ownership in the program.

retention) are targeted to provide this mentorship. Further engagement of graduate students associated with partner laboratories will allow participating students to see opportunities beyond their perceived horizon. Such vertical integration of opportunity is largely absent for underrepresented populations. This near-peer mentoring is essential for the program's sustainability, as it helps create a STEM identity and culture, thereby becoming a visible pipeline for underrepresented high school students to follow and cultivating the sense of belongingness. Near-peer mentoring is a proven way to increase interest in STEM (Tenenbaum et al., 2014; Collings et al., 2014). Mentoring is field specific and using the framework of the International Peer Educator Training Program (IPETP) from the College Reading and Learning Association (CRLA) (Agee and Hodges, 2012), LSAMP Scholars will be trained to serve as mentors to the START Apprentices throughout the summer months, decreasing the "melt" effect.

In addition to peer/near-peer mentors, the START Program is designed to offer students other University of Kentucky campus support services and training. START participants will be trained in best-practice academic coaching and peer mentoring through year-round workshops and reciprocal coaching sessions. Specifically, START participants will engage in Academic Coaching, which operates under the 3:1 Support Model (academic, social-emotional, and access-to-opportunity). Students will develop their own 3:1 Support Plan, including community and university supports, which will be important in the recruitment of underrepresented students to college and maintaining the STEM pipeline. START Apprentices and Ambassadors will not only 
participate in the START Program, but they will also "payit-forward" by serving as volunteers for the UK Summer STEM Experiences (Mohr-Schroeder et al., 2014). START Ambassadors will develop their mentorship and leadership skills, while helping in the mentorship and recruitment of younger underrepresented students into the STEM pipeline.

Teacher participants, named START Teacher Scientists, were planned to be given multiple opportunities throughout the year to engage in professional development focused on advancing strong content knowledge and economic and cultural knowledge related to STEM development in urban and rural high needs areas. In addition to traditional models of professional development such as institutes, workshops, and seminars, START Teacher Scientists were to engage in a three week-long experience in the research laboratory of faculty members at the University of Kentucky or with our business partner, Space Tango. Ultimately, these summer research experiences were to allow the Teacher Scientist to gain authentic research skills in a laboratory setting, an opportunity many were never able to have due to the nature of their teacher preparation program coursework. Furthermore, Teachers Scientists were to build in networking opportunities that could lead to future collaborations with university faculty and industry/community figures that can continue to help strengthen the P20 bridge. Prior to the internship, START Teacher Scientists were to spend one day with the leadership team, preparing for their research experience. The pre-experience day would involve a) presentation of the project goals and objectives, b) overview and analysis of how the NGSS and CCSSM, especially their practices, coincide with their upcoming research experiences, c) laboratory training sessions, and d) meeting with faculty mentors. To help with transfer of knowledge and experience of the summer research experience into the classroom, the researchers who hosted the teachers would be asked to participate in at least one of the following activities: a) delivering seminars to K12 students, introducing them to the research that teacher scholars spent their summers conducting; b) helping teachers prepare research- and inquiry-based investigations that will be implemented during the school year; or c) preparing laboratory visits for a small group of P12 students from underrepresented populations, which will also serve as a recruiting mechanism for future START Scholars.

\section{COVID-19 ADAPTATIONS}

COVID-19 has brought forth many rapid changes in education, as teachers and students were required to work remotely. While COVID-19 eliminated our in-person programmatic approaches, including our planned teacher professional development, the pandemic has allowed us to expand our numbers and ways of reaching students, leaving a hybrid model that will remain after the pandemic ends.

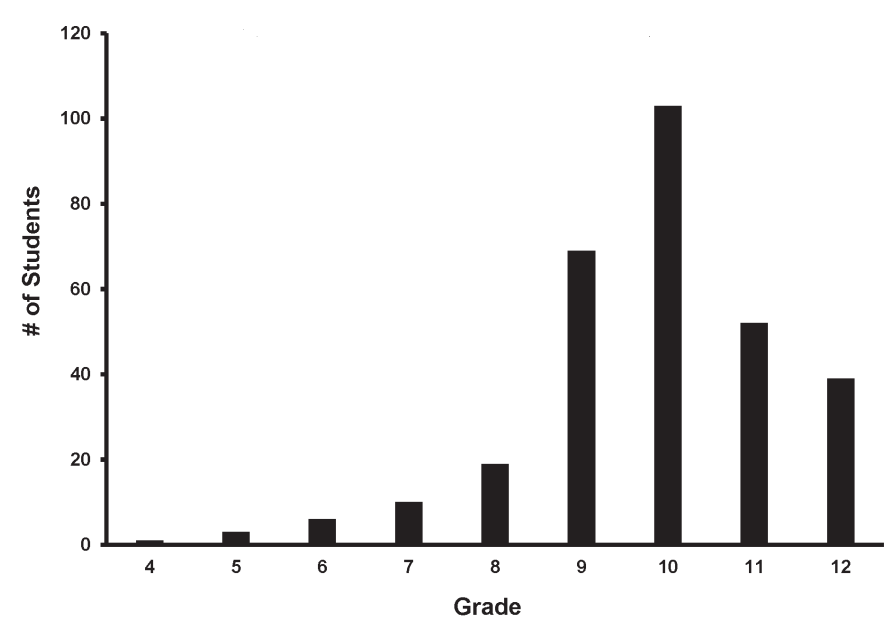

Figure 3. START Ambassador Participation by Grade. Of the 302 START Ambassadors, most of the students are in Grades 9 and 10. Ambassadors will become Apprentices in Grades 11 and 12 if they conduct STEM internships.

This program reached over 302 individuals overall (Figure 3 ) through the implementation of virtual laboratory tours, "Meet a Scientist" discussions, online near-peer demonstrations, at-home learning kits, and online training modules. Of the 302 START Ambassadors, 52 (17.2\%) ethnically identified as Hispanic, and $197(65.2 \%)$ racially identified as non-white (Table 1). Both values represent a significantly higher representation (7.2\% Hispanic, 29.0\% non-white respectively) than in Lexington, Kentucky (US Census, 2019). Our first cohort of Ambassadors had 123 female (40.7\%) participants, which will require more attention in future recruitment. The virtual approach still allowed us to increase opportunity and access for underrepresented populations with preparation and mentorship for higher education, a stronger sense of knowledge for STEM professions, and a greater sense of belonging.

Table 1. Ethnic and Race Demographics of START Ambassadors.

\begin{tabular}{lcccc}
\hline & Female & Male & $\begin{array}{c}\text { Not } \\
\text { reported }\end{array}$ & Total \\
\hline Ethnic & & & & \\
\hline Hispanic & 17 & 27 & 8 & $\mathbf{5 2}$ \\
Non-Hispanic & 106 & 123 & 21 & $\mathbf{2 5 0}$
\end{tabular}

\begin{tabular}{lcccc} 
Race & & & & \\
\hline $\begin{array}{l}\text { American Indian/ } \\
\text { Alaska Native }\end{array}$ & 1 & 0 & 0 & $\mathbf{1}$ \\
Asian & 11 & 10 & 2 & $\mathbf{2 3}$ \\
Native Hawaiian or & 0 & 1 & 0 & $\mathbf{1}$ \\
Other Pacific Islander & & & & \\
Black or African American & 54 & 39 & 10 & $\mathbf{1 0 3}$ \\
White & 30 & 66 & 9 & $\mathbf{1 0 5}$ \\
More Than One Race & 10 & 7 & 0 & $\mathbf{1 7}$ \\
Unknown or Not Reported & 17 & 27 & 8 & $\mathbf{5 2}$ \\
\hline
\end{tabular}




\section{COVID-19 APPROACHES}

Virtual Laboratory Tours and Demonstrations. The University of Kentucky and other community partners have made it possible for START participants to virtually tour research laboratories. Using iPads, student participants gained access to see laboratories on campus and ask questions regarding what occurs in the lab, and how they can potentially get involved post-COVID-19 pandemic. One hundred forty-seven (147) START participants were able to attend laboratory tours and demonstrations, as shown in Table 2. The START program's partner, Space Tango, conducted a 1-hour virtual lab tour of their laboratory and headquarters in Lexington, Kentucky. They showed several aspects of their program ranging from molecular biology to engineering, to other roles in the company. The segments were conducted in 10-minute increments and were led by recent hires, so that the students would be closer in age. At the end of the tour, the employees also shared stories of how they got involved in STEM, and shared information on how to apply to college, look for scholarships, and engage in Space Tango moving forward. This initial tour had 53 students in the area attend virtually. The tour was interactive with prompts and the chat feature running allowed students to ask questions and engage the speakers.

Other online live laboratory demonstrations were conducted at the University of Kentucky. Brain dissections were conducted at the University of Kentucky College of Medicine by graduate students. High school students were guided through one-hour live demonstrations, in which various parts of the brain were shown and their functions were explained. Students were engaged throughout, asking questions often beyond the demonstration, including why the graduate students chose this career path. Some of the biggest takeaways from this specific presentation were that the "brain is really interesting and has a lot of parts to function," "Thank you for teaching us about the brain. I have always been interested in the science behind it so I appreciate this opportunity," "I find all of that stuff so interesting and might even do something with it or go to college for something like that," and that "there are still a lot of unknown things to be discovered." Of the 88 students asked to date, all said they would be interested in more demonstrations related to other scientific topics.

"Meet a Scientist" Discussions. We have initiated with our partner schools 'Meet a Scientist' where students come up with questions of interest which would then be relayed to college students or faculty. A Zoom call is arranged with an entire classroom where we have a frank exchange on the topic of choice. For most students, this is the first of, hopefully, many positive interactions with individuals working in STEM disciplines, thereby increasing the opportunity to see someone like them in a STEM career.

One of the potential barriers to students engaging in
Table 2. START Ambassador virtual engagement activities. These events varied in length, but lasting between 1-2 hours. + FCPS returned to in-person classes in a staggered manner in early 2021, changing lesson plans for classes.

\begin{tabular}{llc}
\hline Date & Demonstration & \# of Students \\
\hline Nov. 2020 & Space Tango & 53 \\
Nov. 2020 & Brain demonstration & 41 \\
Jan. 2021 & Brain demonstration & 37 \\
April 2021 & Meet a Scientist & $6+$ \\
April 2021 & Brain demonstration & $10+$ \\
\hline & Total & $\mathbf{1 4 7}$ \\
\hline
\end{tabular}

STEM disciplines is the notion that scientists and professors are somehow inherently smarter than they are and therefore, they have no right to even imagine these career paths. We established the "Meet a Scientist" program in part to demystify scientists, making them approachable and presenting them as every-day people to whom they may be able to better relate. At the heart of this exercise is to have the students dictate the agenda by coming up with questions they wish to have answered, as a way of handing them control.

A question posed to Dr. Anthony Sinai, a professor of microbiology and co-author was, "How smart do you have to be to be a Professor?" He revealed, much to their surprise, that he himself was a relatively average student in middle and even high school who asked a lot of questions but did not have all the answers. His interest evolved with his knowledge, but he realized that there were some things that he just understood and other things that he struggled with. Chemistry and biology made a whole lot more sense than calculus and computer science. This was stimulated, to some extent, by specific teachers who helped light a spark and keep the flame going. Finding one's spark was the key, as you are unlikely to excel at everything you try. Some things you will simply not get no matter how hard you try, he explained. Nobody, professors included, knows everything at any time, and knowledge increases as one is constantly learning. So, lessons to be learned are follow your strengths and do not get down on yourself if you do not excel at everything you put your mind to. Such discussions presented frankly in an

Table 3. Higher Orbits 'Space At-Home' kits provided to START Ambassadors. These kits/units lasted approximately 4 weeks.

\begin{tabular}{llc}
\hline Date & Name of Kit & Total Provided \\
\hline Oct. 2020 & Space at Home & 1 \\
Nov. 2020 & Edge of Space & 15 \\
Dec. 2020 & Moon Mars & 18 \\
Jan. 2021 & Love of Space & 143 \\
Feb. 2021 & Rockets & 118 \\
Mar. 2021 & History of Space & 95 \\
Apr. 2021 & Astronauts & 48 \\
\hline & Total & $\mathbf{4 3 8}$ \\
\hline
\end{tabular}


approachable manner will give license to students to extend their ambitions and expectations of what they are capable of. Other "Meet the Scientist" interactions planned are based on student requests and include a forthcoming presentation by an immunology doctoral student, who is an underrepresented minority, on vaccination in the context of COVID-19. In addition to discussions on the topic, each presenter will discuss how they got to where they are, their successes, failures and circumstances that impacted the evolution of their career progression.

At-Home Learning Kits. In partnership with Higher Orbits (https://higherorbits.org), we have provided students with at-home learning kits focused primarily on exomedicine and space exploration. Through these online, guided learning kits, START participants have been able to develop teamwork, communication skills, and STEM principles remotely while being able to physically have hands-on activities. The online (Zoom) format has allowed for interaction and engaging conversations with the online guide (an experienced instructor and former astronaut instructor), teachers, STEM professionals, and even astronauts. Further, the materials and videos were saved, so classroom teachers were able to integrate the at-home kits into their classroom instruction when possible.

A total of 438 kits have been provided to START Ambassadors in the seven months they have been available (Table 3 ) and continue to provide learning opportunities. Each kit is based on themes, so each kit is different - students can (and did) participate multiple times gaining diverse experiences. Kits were offered to all of our school partners, with participation open to interested individual students or through classroom participation. The interest in the kits grew as the teachers were able to accommodate the lessons into their schedules during remote learning (Table 3).

Students who participated in the at-home kits were asked to complete a STEM Literacy inventory (available from https://bit.ly/MSSTEMcamp and https://bit.ly/MidSTEMlitPOST) that is based on the Equity-Oriented STEM Literacy Conceptual Framework (Jackson et al., 2021). This Likertscale survey includes questions related to the constructs of the framework - dispositions, STEM identity development, empowerment, critical thinking and problem solving, utility and applicability, and empathy in STEM. All participants who received a kit were invited to participate in the survey, at the beginning and end of the at-home kits, via online Google Form. Approximately $30 \%$ of the participants responded. The survey participants $(\mathrm{N}=54)$ were $40.7 \%$ female and $59.3 \%$ male. A majority of the participants were in high school, with $40.7 \%$ identifying as being in the 9 th grade. Forty-eight percent (48\%) of the students identified as nonwhite (e.g., Black, Latino/a, Asian, Multi-Racial).

Survey results revealed that $20 \%$ of the students indicat- ed they had never had a chance to talk to another adult about STEM. Increasing opportunity and access is an overarching goal for START. Thus, providing at-home kits, which included synchronous Zoom connectivity with many STEM professionals from a variety of backgrounds exposed participating students to opportunities provided by STEM that they had never considered before. Furthermore, most students indicated that their interactions with adults around topics of STEM were restricted to school, an avenue that was largely blocked as a result of the ongoing pandemic. While this is noteworthy, students spend a majority of their time out of school, so we need to continue to find ways to engage students in high quality experiences, not only in the context of the pandemic, but also to supplement interactions in school post-pandemic. The at-home kits met this acute need and are expected to provide critical opportunities for STEM engagement to underserved student populations.

Other interesting findings included that although $68.5 \%$ agreed that they are interested in taking STEM courses, $31.5 \%$ said they were not. Fifty-seven percent $(57 \%)$ of the students agreed that they would like to take a STEM content course in high school or college; however, $42.6 \%$ showed no interest in pursuing additional STEM courses beyond what was required. Further, only $25.9 \%$ of students were very confident in their ability to solve hard problems in STEM. Finally, access to opportunities in STEM is particularly important as over half of the participants, $59.3 \%$ to be exact, want to have a career involving STEM. A core mission of START is to ensure that students interested in STEM retain and expand their interests, while those who currently fail to see its value gain confidence and interest to pursue these disciplines.

The goal of the at-home kits is to increase the overall percentage of participants who are interested in STEM and want to pursue further opportunities. While the quantitative data is currently unavailable, qualitative data collected from the student participants indicated the at-home kits created an opportunity for them to stay engaged in hands-on STEM learning - something they did not have access to during their virtual schooling due to COVID-19. Furthermore, students indicated that they like the opportunity to engage with a variety of STEM professionals, including conversations with astronauts, and indicated that they were now leaning toward pursuing a career in STEM. Parents were then solicited about how the kits generated enthusiasm and interest, while learning about additional paths in STEM. Representative comments from parents said:

"The kids are fully engaged because all the activities are hands on and all the providers are very involved with kids."

"I definitely think that the sessions have allowed my children to see the vast career opportunities that 
link back to STEM. From individuals working at the International Space Station to a Space Historian. These are individuals that my children may have not had the opportunity to hear from directly without the program. This allows them to see the vast opportunities that they can pursue in the future."

"My children are thoroughly engaged in each lesson. They especially love the launches and various speakers. After every lesson they run to share what they've found interesting or new."

"I believe the kits provide an excellent opportunity to engage and access hands on STEM experiences. The kits are varied and cater to every type of learning style. The kits contain everything from projects, puzzles, to books so there is something for every student. There isn't a chance for the kids to get bored because of the range of activities. The kits are comprehensive in nature and contain everything needed, down to the glue."

Online Training Modules. The COVID-19 pandemic challenged our plans to provide in-person training for our START Peer Educators in 2020/2021, however quick thinking and creativity allowed us to transition the trainings to online platforms. We shifted the trainings to our online learning platform, CANVAS, and utilized a self-directed, asynchronous format for the START Peer Educators to receive their Level 1 CRLA (College Reading and Learning Association) Peer Educator and Coaching certification. In addition to this virtual training, all mentors had email and zoom access to the START Teaching Assistant /Academic Coach to answer questions and encourage them as needed.

The original training was planned for two full workdays equaling 15 hours, so we designed the online format to equal the same hours and provide as-close-as-possible education as our in-person training. To accomplish this, the training was broken into nine modules, each one beginning with an introductory video on the topic, including a PowerPoint presentation the trainees can follow. The modules also offer related resources, such as worksheets and exercises that they can utilize for their own growth or use with their future START mentees. Lastly, each module ends with a competency quiz to reinforce the ideas and topics covered in each module. While the START Peer Educators may miss the interactions that in-person trainings can offer, our online format will equip the START Peer Educators to step into their mentorship roles with confidence and enthusiasm.

\section{OTHER PIVOTS}

To maintain a theme of exomedicine throughout the program, START participants have participated in a new webi- nar series produced in Lexington, Kentucky entitled, "Humanity in Deep Space." This series of web panel discussions is an initiative designed to bring together experts from various STEM and non-STEM disciplines to facilitate conversations, that are often overlooked but central, for successful human travel and establishing deep space civilizations. During COVID-19, two live webinars have been hosted to date: 1) Space and Humanities; and 2) Farming on Mars. START students and teachers are welcome to attend and participate.

The COVID-19 pandemic has brought the disruption of in-person education, and access to engaging, authentic learning experiences has been limited significantly. Our laboratory has expanded an undergraduate research training module for the long-term goal of an authentic learning module for introductory students. With the recent attention of biomedical science in the news and ease of genetic sequencing, genetic variants and mutations in health are increasingly being discussed and shared within the public. To address this overall need of providing a virtual authentic learning experience for introductory students in understanding some basic principles of the biomolecular basis of disease, our team is developing a virtual authentic-learning tool which uses data sonification to identify changes and disruptions in protein sequence and its function in the context of a cell.

Finally, to continue strengthening the STEM pipeline, UK START added a three-day workshop on University of Kentucky's campus in June of 2021. This modified summer institute invited area middle and high school STEM Teacher Scientists to attend and receive targeted professional development in the content area as well as pedagogical implications for their current and future classrooms. Usually, the summer institute retreat would be held at a state park, but due to COVID-19 gathering restrictions at the state parks, it was held at UK's campus. The Summer Institute was offered in workshop format - allowing time to dive deep into handson investigations with expert STEM faculty. Investigations are tied to the Common Core for State Standards for Mathematics (CCSSM) and Next Generation Science Standards (NGSS), allowing for ease in implementing into their own classrooms. Professional development credit was available to teachers who attended. Examples of workshops offered by STEM faculty included: What Waves in a Wave; Electromagnetic interference and Spread Spectrum Clock Generation; Glow Big or Glow Home! (fluorescence experiment); Coding without a computer; Using mathematical modeling to investigate and predict the Flint Hill water disaster; Using Systems Thinking in STEM Education; and applying systems thinking and modeling based inquiry in Biology. Each participant received a classroom kit of materials used at the workshop to further promote the lessons being carried out in the classroom. 


\section{CONCLUSION}

The START Program offers a sustainable way to fill the diversity gap in the STEM pipeline as it is built upon a rich interdisciplinary collaboration, further reinforcing the opportunities to network and form a STEM culture. By offering a wide variety of experiences, including year-round nearpeer mentorship, academic coaching, and authentic research opportunities, START students will not only increase their skill sets in STEM disciplines, but they will also increase their confidence and sense of belonging within the STEM community. By utilizing the three aims of the START Program, we expect to increase the recruitment and retention of underrepresented populations within STEM, while reducing the "melt" phenomenon. While this collaboration was challenged during COVID-19, the leadership team worked together to pivot to new ideas and partnerships, while holding to the vision of creating opportunity and access to high quality STEM experiences for all our students, especially those from underrepresented populations. Currently, we are evaluating the effectiveness of these pivots, and will track students longitudinally through the high school portion of the program as in-person content is returning. Finally, by combining virtual content with the originally planned in-person authentic experiences, the START Program model has emerged as a hybrid with a sustainable structure, while reaching more students in the community than possible with face-to-face interactions alone, that can be adopted by other institutions locally, regionally, and nationally to address this critical gap in the STEM pipeline.

\section{AUTHOR INFORMATION Corresponding Author}

Luke H. Bradley. MN214 Chandler Medical Center, 800 Rose St., Lexington, KY 40536-0298. 1hbradley@uky.edu

\section{Author Contributions}

The manuscript was written through contributions of all authors. All authors have given approval to the final version of the manuscript.

\section{ACKNOWLEDGMENTS}

We thank our partners: Academies of Lexington, STEAM Academy, LEAP Academy, Fayette County Public Schools, Advance Kentucky, KY-WV LSAMP Program (NSF HRD 1826763), Kentucky Science and Technology Company, Higher Orbits, and Space Tango. We also thank Alethea Bernard, Demetria Blair, Kris Kimel, Michelle Lucas, and Willie Pearson for their constructive discussions and feedback; Danielle Rosales from Space Tango for organizing a virtual tour of their facilities; and the University of Kentucky Department of Neuroscience graduate students
Colleen Bodnar, Alex Early, Jelena Juras, Jessica Newton, Lydia Strattan, and Chase Taylor for participating in the online demonstrations.

\section{FUNDING SOURCES}

This project is made possible by a Science Education Partnership Award (SEPA), Grant Number R25 GM132961, from the National Institute of General Medical Sciences (NIGMS), National Institutes of Health (NIH). Its contents are solely the responsibility of the authors and do not necessarily represent the official views of the NIGMS or NIH. Additional support was received from the Chellgren Endowment at the University of Kentucky (LHB).

\section{ABBREVIATIONS}

CCSSM: Common Core for State Standards for Mathematics; CRLA: College Reading and Learning Association; IPETP: International Peer Educator Training Program; ISS: International Space Station; START: LSAMP: Louis Stokes Alliance for Minority Participation; NGSS: Next Generation Science Standards; NIGMS: National Institute of General Medical Sciences; NIH: National Institutes of Health; SEPA: Science Education Partnership Award; START: STEM Through Authentic Research and Training; STEM: Science, Technology, Engineering, and Mathematics; UK: University of Kentucky

\section{REFERENCES}

Agee, K., and Hodges, R. (2012). CRLA Tutor and Mentor Training Handbook. Cengage Learning, Columbus, $\mathrm{OH}$.

Castleman, B., and Page, L. (2015). Summer nudging: Can personalized text messages and peer mentor outreach increase college going among low-income high school graduates. Journal of Economic Behavior and Organization, 115, 144-160.

Chang, M. J., Sharkness, J., Hurtado, S., and Newman, C. B. (2014). What matters in college for retaining aspiring scientists and engineers from underrepresented racial groups. Journal of Research in Science Teaching, 51(5), 555-580.

Collings, R., Swanson, V., and Watkins, R. (2014). The impact of peer mentoring on levels of student wellbeing, integration and retention: A controlled comparative evaluation of residential students in UK higher education. Higher Education, 68(6), 927-942.

Edmonds-Cady, C., and Sosulski, M. R. (2012). Applications of situated learning to foster communities of practice. Journal of Social Work Education, 48(1), 45-64. 
Elam, M. E., Donham, B. L., and Soloman, S. R. (2012). An engineering summer program for underrepresented students from rural school districts. Journal of STEM Education: Innovations and Research, 13(2), 35-44.

Fayer, S., Lacey, A., and Watson, A. (2017). STEM occupations: past, present, and future. Retrieved from Bureau of Labor Statistics

Huggett, B. (2018) Biotech's pale shadow. Nature Biotechnology $1,20-30$.

Hussar, B., Zhang, J., Hein, S., Wang, K., Roberts, A., Cui, J., Smith, M., Bullock Mann, F., Barmer, A., and Dilig, R. (2020). The condition of education 2020. U.S. Department of Education. Washington, DC: National Center for Education Statistics.

Jackson, C., Mohr-Schroeder, M. J., Bush, S., Maiorca, C., Roberts, O. T., Delaney, A., Fowler, A., and Yost, C. (2021). An equity-based STEM literacy conceptual framework. International Journal of STEM Education, 8(38).

Johri, A., and Olds, B.M. (2011). Situated engineering learning: Bridging engineering education research and the learning sciences. Journal of Engineering Education, 100(1), 151-185.

Jong, C., Priddie, C., Roberts, T., and Museus, S. D. (2020). A Review of Research on Educational Experiences and Outcomes for Racial and Ethnic Minorities. In C. Johnson, M. Mohr-Schroeder, T. Moore, and L. English, Handbook of Research on STEM Education. New York: Routledge.

Kemple, J., and Willner, C. (2008). Career Academies: Long-term impacts on labor market outcomes, educational attainment, and transitions to adulthood. Clearinghouse for Labor, Evaluation, and Research. New York: MDRC.

Maxwell, N., and Ruben, V. (2002). High school career academies and post-secondary outcomes. Economics of Education Review, 21(2), 137-152.

Mohr-Schroeder, M., Jackson, C., Miller, M., Walcott, B., Little, D.L., Speler, L., Schooler, W., and Schroeder, D.C. (2014). Developing middle school students' interests in STEM via summer learning experiences: See Blue STEM Camp. School Science and Mathematics, 114(6), 291-301.

Muzzatti, B., and Agnoli, F. (2007). Gender and mathematics: Attitudes and stereotype threat susceptibility in Italian children. Developmental Psychology, 43(3), 747-759.

Roberts, O. T., Jackson, C., Mohr-Schroeder, M. J., Bush, S. B., Maiorca, C., Cavalcanti, M., Schroeder, D. C., Delaney, A., Putman, L., and Cremeans, C. (2018). Students' perceptions of STEM learning after participating in a summer informal learning experience. International Journal of STEM Education, 5(35). doi: 10.1186/s40594-018-0133-4

Strayhorn, T. (2011). Bridging the pipeline: Increasing underrepresented students' preparation for college through a summer bridge program. American Behavioral Scientist, 55(2), 142-159.
Tenenbaum, L.S., Anderson, M.K., Jett, M., and Yourick, D.L. (2014). An innovative near-peer mentoring model for undergraduate and secondary students: STEM Focus. Innovative Higher Education, 39, 375-385.

Tinto, V. (2007). Research and practice of student retention: What next? Journal of College Student Retention: Research, Theory and Practice, 8(1), 1-19.

U.S. Census QuickFacts for Lexington and Fayette County, Kentucky. (2019) Retrieved from: https://www.census.gov/ quickfacts/lexingtonfayettekentucky

U.S. Department of Commerce Economics and Statistics Administration. (2017). Retrieved from: http://www.esa.doc.gov/ sites/default/files/stem-jobs-2017-update.pdf 